\title{
Successful bronchial artery embolization for refractory esophageal bleeding after failed endoscopic therapy
}

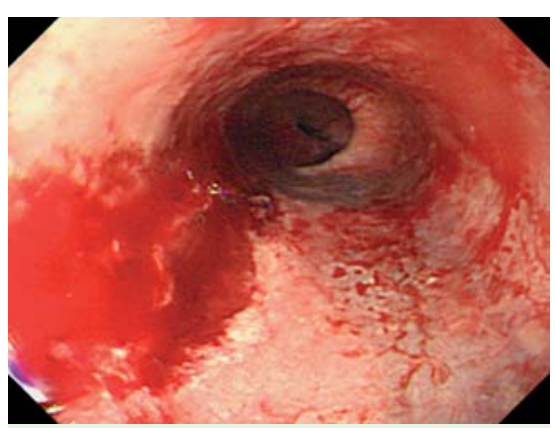

Fig. 1 Endoscopic view of esophagus. Active arterial bleeding is apparent from a long laceration of the lower esophagus.

A 51-year-old man with chronic alcoholism was admitted to the emergency unit with hematemesis $(750 \mathrm{~mL})$. Emergency endoscopy revealed active bleeding from a longitudinal laceration in the lower esophageal wall. The laceration was approximately $3.5 \mathrm{~cm}$ long and located $35 \mathrm{~cm}$ from the incisor teeth ( Fig. 1). Despite the application of more than 30 hemoclips and several rubber bands, bleeding was not controlled. As he was hemodynamically unstable, a transfemoral angiogram was performed to find the bleeding artery. The celiac angiogram showed that the left gastric or other arteries did not supply the area being clipped. We found dye leakage from a small branch of the right bronchial artery ( $\bullet$ Fig. 2a). We embolized the bronchial artery with two 2-cm-long helical coils (Hilal Embolization Microcoil ${ }^{\mathrm{TM}}$, Cook, Bloomington, Indiana, USA). A follow-up angiogram revealed an occluded bronchial artery with no leakage ( $\mathbf{F i g . 2} \mathbf{b}$ ). Follow-up endoscopy 3 days later showed a healed ulcer at the laceration site ( $\bullet$ Fig. 3). The patient was discharged without further complications.

Although the majority of Mallory-Weiss tears resolve spontaneously, rare cases of severe, active bleeding may be fatal if left untreated [1]. In our case, the laceration site was relatively long for a MalloryWeiss tear. Interestingly, the artery feeding the esophageal laceration was the right bronchial artery around the middle esophagus, instead of the left gastric or splenic artery [2]. Therefore, if one cannot find the feeding artery in Mallory-Weiss
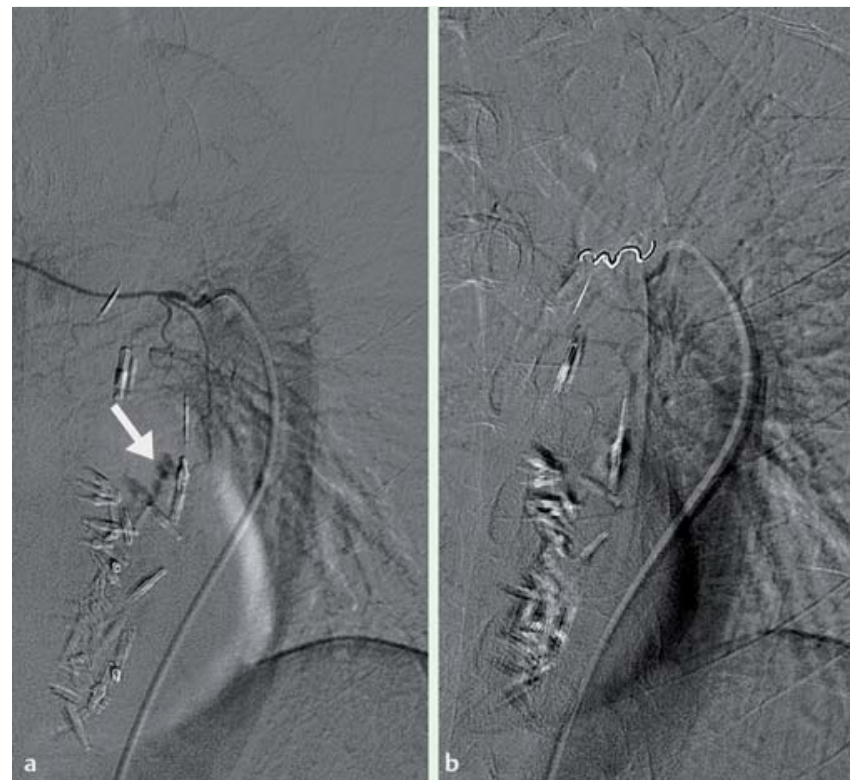

Fig. 2 Selective right bronchial arterial embolization. a Contrast media leaked from the small branch of the right bronchial artery (arrow). b After coil embolization, the bronchial artery was occluded and no dye leakage was seen.

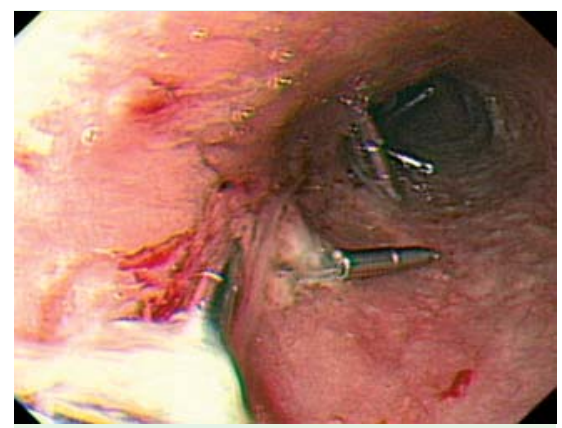

Fig. 3 Endoscopic view after coil embolization. Follow-up endoscopy 3 days later showed a healed ulcer at the laceration site.

syndrome on a celiac angiogram, a thorough thoracic angiogram should be performed.

When performing transcatheter esophageal bleeding control, it is important to understand the esophageal blood supply according to lesion location. In addition, it is useful to note individual variation in blood supply to the esophagus. The midesophagus is usually supplied from branches of bronchial arteries or directly from the thoracic aorta.

Thus, our case demonstrates that coil embolization is an effective, safe alternative method for severe active bleeding in Mallory-Weiss syndrome if endoscopic therapy fails.
Endoscopy_UCTN_Code_TTT_1AO_2AD

E. M. Kim, J. H. Lee, J. K. Sung,

S. H. Kang, J. I. Kim, H. S. Moon,

B. S. Lee, S. H. Kim, H. Y. Jeong

Department of Internal Medicine,

Chungnam National University School of

Medicine, Chungnam National University Hospital, Daejeon, Korea

\section{References}

1 Myung SJ, Kim HR, Moon YS. Severe MalloryWeiss tear after endoscopy treated by endoscopic band ligation. Gastrointest Endosc 2000; 52: 99- 101

2 Fisher RG, Schwartz JT, Graham DY. Angiotherapy with Mallory-Weiss tear. Am J Roentgenol 1980; 134: 679-684

\section{Bibliography}

DOI 10.1055/s-0029-1214794

Endoscopy 2010; 42: E42

(c) Georg Thieme Verlag KG Stuttgart · New York . ISSN 0013-726X

\section{Corresponding author}

\section{J. K. Sung, MD, PhD}

Division of Gastroenterology

Department of Internal Medicine

Chungnam National University Hospital

33, Munhwa-ro

Daejeon, 301-721

Korea

Fax: +82-422544553

jksung69@cnuh.co.kr 